\title{
Worker Health and Safety in Rubber Shoe Production
}

\author{
Nurettin Akcakale (Corresponding author) \\ Bolu Abant Izzet Baysal University, Gerede Vocational School, \\ 14900 Gerede Bolu, Turkey \\ E-mail: akcakale_n@ibu.edu.tr \\ Ayhan Milli \\ Bolu Abant Izzet Baysal University, Gerede Vocational School, Bolu, Turkey \\ 14900 Gerede Bolu, Turkey \\ E-mail: ayhan.milli@ibu.edu.tr \\ Ihsan Ates \\ Marmara University, Institute of Science and Technology, \\ Kadikoy, Istanbul, Turkey \\ E-mail: ihsanates@,hotmail.com
}

\begin{abstract}
The elastomers, which are called natural and synthetic rubber, have a wide usage area in the industry due to their unique properties.

Rubber; they are used in many areas of industry, especially vehicles. Additive and fillers with many different properties are added during production to ensure that the products to be produced from these materials have the required properties.

One of the applications of rubber-type elastomers is the footwear sector. Shoes are worn for protection against external conditions. The material that covers the bottom of the shoe from one end to the other and is in contact with the ground when it is worn is called the shoe sole.

Rubber base with elastomer properties, the importance of occupational health and safety rules in manufacturing sector is increasing day by day. In this study, the occupational diseases caused by chemical substances which are used in the production of rubber shoe sole and the methods of protection from them are explained.

Employers and employees have responsibilities to reduce the risk of occupational accidents and occupational diseases in the manufacture of rubber shoe sole. In this article; According to the required technical formula, the preparation of the rubber, additives and fillers in the mixture in the preparation of dough and the effects of gas, dust, smoke and steam on the environment and human health during the vulcanization of the prepared dough under high temperature with suitable chemical cookers were examined.

It also covers the literature on occupational health risk groups, which employees are interested, and what occupational safety measures should be taken on a sectoral basis.
\end{abstract}

Keywords: Shoe soles, Rubber shoe soles, Occupational health and safety, Production of rubber soles.

DOI: $10.7176 / \mathrm{JSTR} / 5-2-44$

\section{Kauçuk Ayakkabı Tabanı İmalatında İşçi Sağlığı ve Güvenliği}

\section{Özet}

Doğal ve sentetik kauçuk olarak anılan elastomerler kendilerine has üstün özellikleri nedeni ile endüstride geniş bir kullanım alanına sahiptirler.

Kauçuklar; taşıtlar başta olmak üzere endüstrinin pek çok alanında kullanılırlar. Bu malzemelerden

403 | P a g e

www.iiste.org 
üretilecek ürünün gerektirdiği özelliklere sahip olabilmesi için işlenme sırasında çok sayıda ve değişik özelliklere sahip katkı ve dolgu maddeleri katılır.

Kauçuk türü elastomerlerin kullanım alanlarından biride ayakkabı sektörüdür. Ayakkabılar ayağı dış şartlardan koruma amaçlı olarak giyilir. Ayakkabının altını bir uçtan bir uca örten ve giyildiğinde yer ile temas eden malzemelere, ayakkabı tabanı denilmektedir.

Elastomer özellikli kauçuk taban imalat sektöründe iş sağlı̆̆ ve güvenliği kurallarına duyulan önem gün geçtikçe artmaktadır. Bu çalışmada kauçuk ayakkabı tabanı imalatında kullanılan hamuru oluşturan kimyasal maddelerin yola açabileceği meslek hastalıklarının neler olduğu ve bunlardan korunma yöntemleri anlatılmıştır.

Kauçuk ayakkabı taban imalatında iş kazaları ve meslek hastalıklarının azaltılması için işverenlerin ve çalışanların yerine getirmesi gereken sorumlulukları bulunmaktadır. Bu makale çalışmasında; istenilen teknik formüle göre hamur hazırlamada karışıma giren kauçuk, katkı ve dolgu maddelerinin bamburide hazırlanması ve hazırlanan hamurun yüksek sıcaklık altında uygun kimyasal pişiricilerle vulkanizasyonu (pişirilmesi) esnasında ortaya çıkan gaz, toz, duman ve buharın çevre ve insan sağlığı üzerine etkilerinin neler olduğu incelenmiştir.

İş sağlı̆̆ açısından risk grupları, hangi çalışanları ilgilendirdiği, sektör bazında alınması gereken iş güvenliği önlemlerinin neler olması gerektiği konularındaki literatür araştırmasını kapsamaktadır.

Anahtar Kelimeler: Ayakkabı tabanları, Kauçuk ayakkabı tabanları, Kauçuk taban üretimi, İş sağlığı ve güvenliği.

\section{Giriş}

Ayakkabı taban malzemelerini üretildikleri maddelere göre farklı kategorilere göre sınıflandırmak mümkündür. Genel olarak taban malzemeleri doğal ve sentetik taban malzemeleri diye iki gruba ayrılır. Belli başlı taban malzemeleri; kauçuk, poliüretan (PU), polivinilklörür (PVC), etilvinilasetat (EVA), faylon, termokauçuk (TR), termopoliüretan (TPU), kösele, neolit vb dir [1].

Ayakkabı taban malzemesi seçiminde; tüketicilerin fantezi istekleri, yapım kolaylıkları (imalata uygun olma), ucuzluk, dayanıklılık, temin edilebilme kolaylığı vb faktörler etkilemektedir. Bütün bu faktörler göz önünde bulundurulduğunda ayakkabı tabanlarında en çok kullanılan malzeme grubu \% 32 ile kauçuklardır [1, 2]. Kauçuklar ayakkabı sanayiinde taban malzemesi olarak kullanıldıkları gibi aynı zamanda çizme, bot ve terliklerin yekpare üretiminde de kullanılmaktadır.

Ülkemizde yılda 280 milyon çift ayakkabı üretilmektedir [3].

\section{Kauçuk ve Elastomer Kavrami}

Kauçuklarda kendi arasında doğal ve sentetik olmak üzere iki gruba ayrılır. Temel bileşeni "poliizopren" olan doğal kauçuk, ekvator çevresinde yetişen tropikal hevea brasiliensis kauçuk ağacının kabuğundan akan sıvıdan (lateks) elde edilir. Sentetik kauçuklar ise petrol ürünlerinden elde edilir. Sentetik kauçukların kullanım yerinin özelliğine göre pek çok türü vardır.

Dünyada yılda 12 milyon tonun üstünde kauçuk üretilir; bunun yaklaşık 1/3’ü doğal kauçuk olup, geri kalanı petrolden elde edilen kimyasal maddelerle yapılan sentetik kauçuklardır [4]. Dünyada üretilen kauçuğun yaklaşık olarak \% 2'si ayakkabı sektöründe kullanılmaktadır [5]

Kauçuklar oda sıcaklığında amorf, ortam sıcaklığından daha düşük camsı geçiş sıcaklığı olan ve seyrek çapraz bağlanabilerek elastomer haline dönüşebilen polimer maddelerdir. Kauçuklar karmaşık halde duran molekül zincirlerinin uzatılabilir özellikleri nedeniyle, oda sıcaklığında önemli bir kauçuk elastikliğine sahiptirler. Ancak sıcaklık arttıkça, malzemenin akışkanlığ 1 artar ve giderek termoplastik davranışlar gösterir [6].

Kauçuklar en genel anlamda doğal ve sentetik kauçuklar olarak sınıflandırılabilir. Yaygın bir sınıflandırma da kullanım yaygınlığına göre yapılandır. Kullanım yaygınlığına göre, kauçuklar genel kullanım kauçukları, özel kullanım kauçukları olarak sınıflandırılabilir. Genel kullanım kauçukları, kauçuk tüketiminin \% 95'ini oluşturmaktadır [2].

Pişirilmeden kullanılan kauçuk, çok yapışkan, kopma dayanımı düşük ve kirleten malzeme görünümündedir. İlk defa Amerika'da Charles Goodyear kauçuğun kükürt ile karıştırılıp ısıtıldığında yapışkan olmayan, yüksek elastikiyeti ve iyi mekanik özellikleri olan bir malzeme haline dönüştüğünü 
keşfetti. Aynı yıllarda İngiliz Thomas Hancock'da benzer çalışmaları yaptı. Böylece birlikte vulkanizasyonu keşfetmiş ve dünyaya duyurmuş oldular.

Kükürt ile vulkanizasyonun ilk adımı kauçuk ile kükürdün birleşmesinden oluştu. Bu keşfin sonunda dünyada büyük bir kauçuk eşya kullanımı başlanmıştır. Kauçuğun kükürtle pişirme sistemi çok yavaş olup uzun süreler aldığından bu süreyi azaltmak için yapılan araştırmalar sonucu, metal oksitlerin (çinko oksit) vulkanizasyonu belirgin bir biçimde hızlandırdığını sonucunu ortaya çıkarmıştır. Karışımın geliştirilmesinde ikinci adımı; kauçuk, kükürt, çinko oksit birleşmesinden oluşturulmuştur. Daha sonra karışımda organik hızlandırıcılar (akseleratör) kullanılmaya başlanmıştır. Kauçuklarda kullanılan bütün bu maddeler hem vulkanizasyonun hızlanmasına hem de mekanik özelliklerin artmasını sağlamıştır. İlk ticari akseleratör 1921 yılında bulunan "merkaptobenzotiazol" dir [7]. Bu akseleratörün bulunuşu ile kauçuklarda yaşlanma özelliğini azaltmak için kükürt kullanım miktarı azalmıştır, daha kısa sürede pişme periyodu sağlanmıştır, önceden pişme eğilimi azalmıştır, işlenebilme özellikleri artmıştır ve malzemelerin mekanik özellikler artmıştır.

Organik hızlandırıcıların bulunuşu ile birlikte üçüncü tip karışım elde edilmiştir. Buda; kauçuk, kükürt, çinko oksit, organik hızlandırıcıların karışımdan oluşmaktadır. Bu şekilde hazırlanmış bir karışımın işlenmesi zor olmaktadır. İşlenmeyi kolaylaştırmak için mastikasyon işlemi gerekmektedir. Mastikasyonun keşfi ile kauçuğa dolgu maddelerinin daha kolay katılması sağlandı. Bu şekilde kauçuğun dayanımı ve sertliği artırılmış oldu. Dolgu maddelerinin kauçuğa daha kolay katılmasını sağlamak ve sertliği düşürmek amacı ile bu kez yumuşatıcıların kauçuğa ilave edilmesi gerekliliği bulundu. $\mathrm{Bu}$ çalışmalar neticesinde dördüncü evrede; kauçuk, kükürt, çinko oksit, organik hızlandırıcılar, dolgu maddeleri ve yumuşatıcılardan oluşturuldu.

Daha sonra bazı organik antioksidantların, kauçuğun yaşlanmasına mani olan özellikleri keşfedildi. Yine bu sıralarda tabii kauçuk içerisindeki hidrokarbon olmayan kısımlardaki yağ asitlerinin, hızlandırıcıların etkinliğine yardımcı olduğu ortaya çıkarıldı. Stearik asidin ilk olarak tabii kauçuk, daha sonra sentetik kauçuklu karışımlara katılması pratik hale geldi. Vulkanizasyonun kükürtlü pişirme sistemi ile (kükürt, organik hızlandırıcı, çinko oksit, stearik asit) yapılması en yaygın çapraz bağlanma sistemini oluşturdu. Karışımdaki beşinci evre ve temel reçete; kauçuk, kükürt, çinko oksit, organik hızlandırıcılar, dolgu maddeleri, yumuşatıcılar, antioksidantlar, yağ asitleri haline dönüştü.

\section{Kauçuk Taban Hamurlarinda Karişima Giren Maddelerin Sistematiği}

Kauçuk karışımı, istenilen özelliklere göre ayarlanmış kauçuk ve diğer hammaddeler ile katkı maddelerinden oluşan vulkanize edilebilen bir karışımdır. Kauçuk karışımından istenilen özellikler; bitmiş mamulden istenilen özellikler, uygulanacak metot ve kullanılacak makine ve ekipmana uygunluk açısından beklenen özellikler ve rekabet edebilmesi bakımından maliyet özelikleridir.

Maksada uygun olarak seçilmiş ve birbirleriyle oransal olarak ayarlanmış maddeler topluluğu "Reçete" veya "Formül" olarak isimlendirilir [8, 9, 10, 11]. Fonksiyonel olarak kauçuk karışımına giren maddelerin sistematiği şöyledir:

- Kauçuk (lar)

- Vulkanizasyon maddeleri

Kür maddeleri

(Hızlandırıcılar, Aktivatörler, Geciktiriciler)

- Aktif (takviye edici) yada aktif olmayan dolgu maddeleri

-Proses kolaylaştırıcılar

-Yaşlanmayı önleyiciler ve koruyucular

-Yumuşaticilar

-Şişiriciler

-Boya maddeleri

-Özel amaçlı maddeler.

Kauçuk formül karışımlarına değişik fiziksel, mekanikse, kimyasal vb özellikler kazandırmak için farklı malzemeler katılır. Bu malzemeler dolgu ve katkı maddeleri olarak isimlendirilir.

Dolgu maddeleri; kauçuklara kuru toz halinde katılan çok küçük tane boyutlu maddelere dolgu maddeleri denir. Kauçuğu kuvvetlendirme etkilerinin yanında, işlenebilme özelliği geliştirmek, ekonomik karışımlar oluşturmak ve renklendirme amacı ile kullanılırlar. Dolgu maddelerini, güçlendirici etkisi olanlar, yarı güçlendirici etkili, salt dolgular diye üçe ayırmak mümkündür.

405 I $P$ a g e

www.iiste.org 
Katkı maddeleri; kauçukta belli özellikler sağlamak için az miktarlarda ilave edilen maddelerdir. Bunları; vulkanizasyon maddeleri (hızlandırıcılar, aktivatörler, geciktiriciler), yumuşatıcılar (yağlar), proses kolaylaştırıcılar (hidrokarbonlar, yă̆ asitleri, sentetik reçineler, organik thio karışımlar), yaşlanma önleyiciler ve koruyucular (antiozanat, antioksidant), şişiriciler, boya maddeleri (pigmentler), koku vericiler, özel amaçlı maddeler diye gruplandırmak mümkündür.

\section{Kauçuk Prosesleri}

Kauçuktan imal edilen parçaların hemen hepsi organik ve inorganik malzemelerin ezilmiş ve sakızlaşmış elastomere karıştırılarak ve sonrasında vulkanize edilerek elde edilir. Bu süreç plastik, poliüretan gibi benzer polimerle çalışmaktan daha uzun ve zor çalışmayı gerektirir.

Her zamanki kullanılan ilave malzemelerin, teknik özelliklerin elde edilebilmesi ve ekonomi sağlaması için titizlikle seçilmesi gerekmektedir. Her geçen gün artmakta olan teknolojik gelişmeler kauçuk parçaları, daha verimli olmaya zorlamakta hatta mecbur tutmaktadır. Araç lastiği, hortumlar, kayışlar, silecek lastikleri, contalar, takozlar ve diğer kauçuk parçalar bugünkü teknoloji ve kalitede olmasa otomotiv sanayi, beyaz eşya sanayi bugünkü gibi verimli olmaları şüpheliydi. Kalitesi daha az önemli veya önemsiz kauçuk parçalar ekonomi sağlamak için hurda lastikten elde edilen rejenere dolgular veya yağlar ile ucuzlatılabilse de işleme sürelerindeki titizlik değişmeyecektir [12].

Ayakkabı taban imalatı yapan işletmelerin kapasitesi küçükte olsa kullanılan ekipman ağır makine sınıfına girmektedir. Önce karışım hazırlanır sonra şekillendirilir ve en sonunda vulkanize edilir (pişirilir). Elde edilen ürünün cinsine ve yapılışına göre değişen çapak temizlemek veya yüzey parlatmak gibi işlemlerden geçerek ambalajlanır. Kauçuk taban imalatı iki aşamada gerçekleşir. Önce belli formülasyona göre karışım hazırlanır. İkinci aşamada ise karışımın ekstrüzyon ve kalenderleme yöntemi ile şekillendirilmesidir. İşlem vulkanizasyon ile tamamlanır. Bazı mamullerde vulkanizasyon sonrası bitirme işlemleri yapılır. Karıştırma, kauçuk hamuruna konulan tüm bileşenlerin belli bir düzende ilave edilerek, homojen bir kitle (hamur) haline getirilmesidir. Karıştırma işlemi için çeşitli karıştırıcılar kullanılmaktadır. Karıştırmadan maksat; karışıma giren malzemelerin enaz değişiklikle kauçuk karışımını oluşturmasını, tozların homojen bir dağılım yapmalarını ve işlemin çabuk ve ucuz olmasını sağlamaktır. Karıştırıcılar açık karıştırıcılar ve kapalı karıştırıcılar (bambury) diye ikiye ayrılır. Karıştırma işleminden sonra kalenderleme isimi verilen işlem ile kauçuk hamurundan istenilen kalınlıklarda levha elde etmek için uygulanan bir işlemdir.

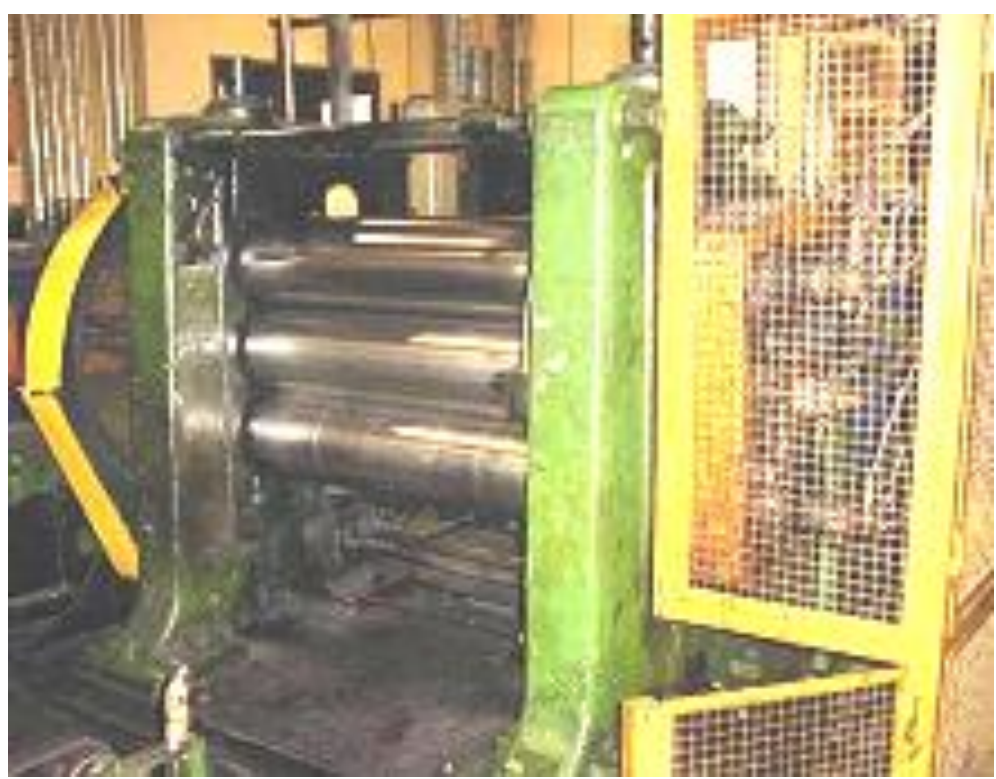

Şekil 1. Hamur hazırlama makinesi [2] 


\subsection{Banbury}

Banbury, özellikle plastik ve kauçuk sanayiinde temel makinelerinden biridir. Hammadde tanklarından veya bölümlerinden, hortumu yardımıyla aldığı hammaddeyi, üretilecek mamulün tipine göre değişik sıcaklık ve basınçlarda, mikserlerde karıştırarak hamur haline getirir. Çalışmalarda; karışım hazırlama banbury iç sıcaklığı malzemelerin özelliklerine göre değişiklik arz etmektedir.

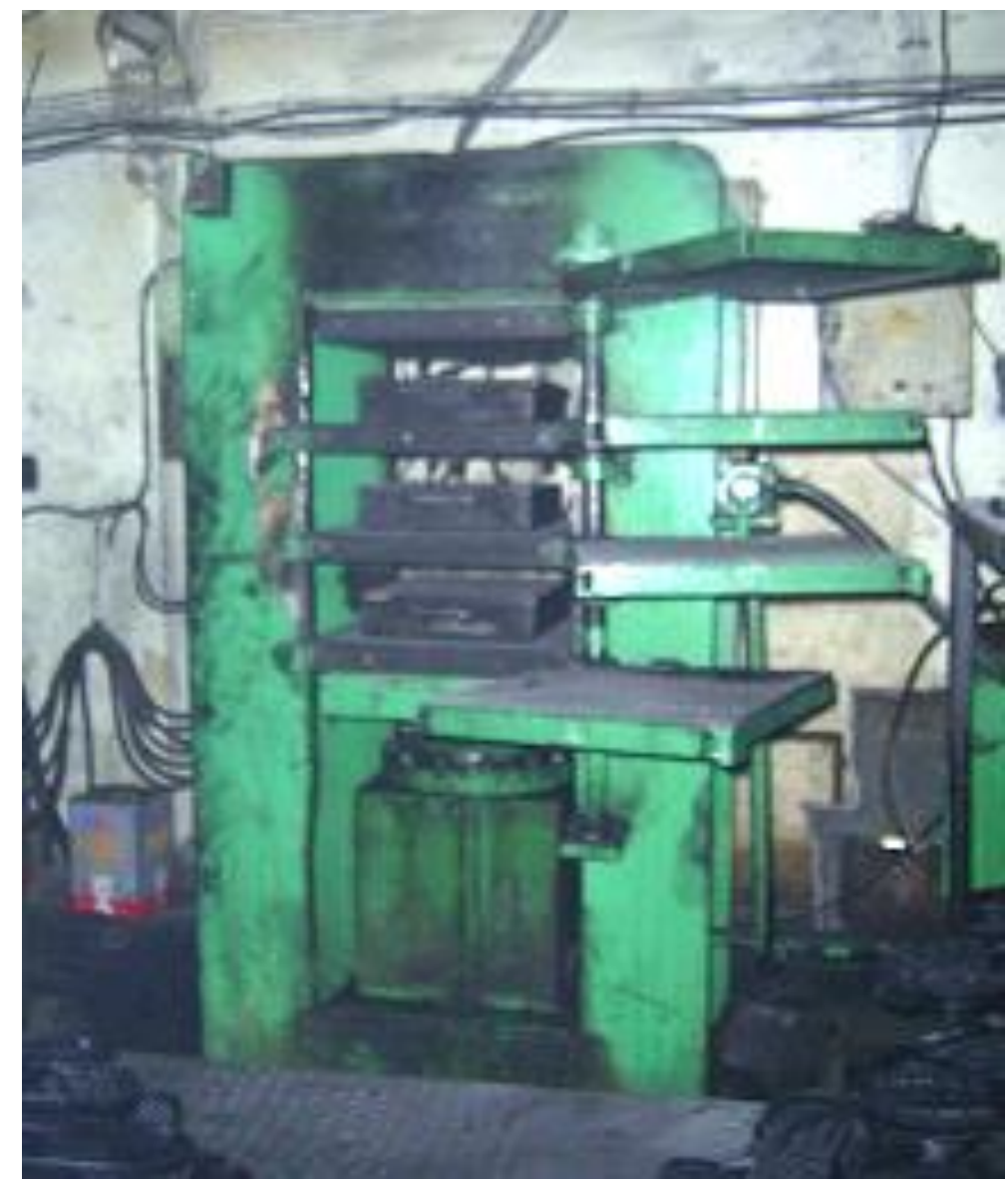

Şekil 2. Vulkanizasyon presi [2]

\subsection{Vulkanizasyon Presi ve Kalıplama}

Elastomer tip kauçukların çapraz bağ (vulkanizasyon) oluşumunda kullanılan preslerdir. Vukanizasyon (kalıplamanın) kompresyon, transfer ve enjeksiyon çeşitleri vardır. Her üç yöntemde de kauçuk hamuru kalıp içinde sıcaklık ve basınç altında vulkanize olur. Vulkanizasyon süresi karışımın formülasyonuna, kalıp sıcaklıklarına bağlıdır. Kauçuk ayakkabı tabanları için kalıp sıcaklıkları $150-220{ }^{\circ} \mathrm{C}$ arasında değişmektedir. Şekil 2'de ayakkabı taban vulkanizasyon işlemleri için elektrik enerjisi ile çalışan otomatik zaman ayarlı bir hidrolik pres görülmektedir.

Şekil 3'de vulkanizasyon işlemi için sıcak prese kauçuk levhalarının yerleştirilmesi görülmektedir. Buraya yerleştirilen kauçuk malzeme miktarı önceden hesaplanarak konulmalıdır. Az malzeme konulması bozuk ürün çıkmasına, çok malzeme konulması ile aşırı işçiliğe ve malzeme israfına sebep olmaktadir. 


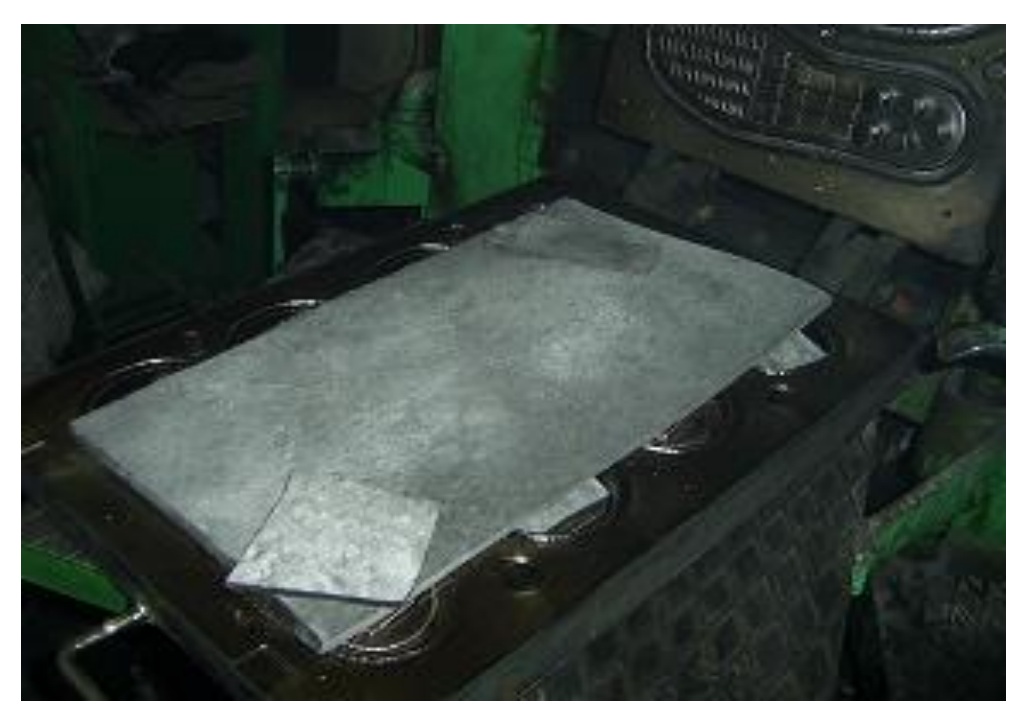

Şekil 3. Sıcak prese kauçuk levhalarının yerleştirilmesi [2]

\subsection{Bitirme Operasyonları (Çapak Alma)}

Taban malzemelerinin kalıptan çıktıktan sonra son haline getirilmesi için kalıpların birleşme yerlerinden taşan çapakların makas, falçata vb bir yöntemle alınması genel bir uygulamadır. Gelişmiş kalıp sistemlerinde ürünler çapaksız olarak ta imal edilebilirler. Fakat bunun için çok hassas pres ve karışımlar gerekir. Daha kolay çapak alma işlemi için yapılmış makineler vardır. Bazı taban malzemelerinin çapakları alındıktan sonra altlarına veya dış kenarlarına görsellik katmak amacıyla finisaj uygulanabilir. Pişirme işlemi biten ve presten çıkarılan tabanlardan artan ve dışarı çıkan kauçuk çapağına sahip kauçuk parçasının hatalı bir görünümü vardır ve bunların yok edilmesi gerekir. Vulkanizasyon işleminden sonra kauçuk taban parçalarının üzerindeki çapakların alınması işlemi bitirme operasyonu olarak tanımlanmaktadır. Şekil 4'de vulkanizasyon işleminden sonrası presten çıkarılmış ve bitirme işlemi bekleyen tabanlar görülmektedir.

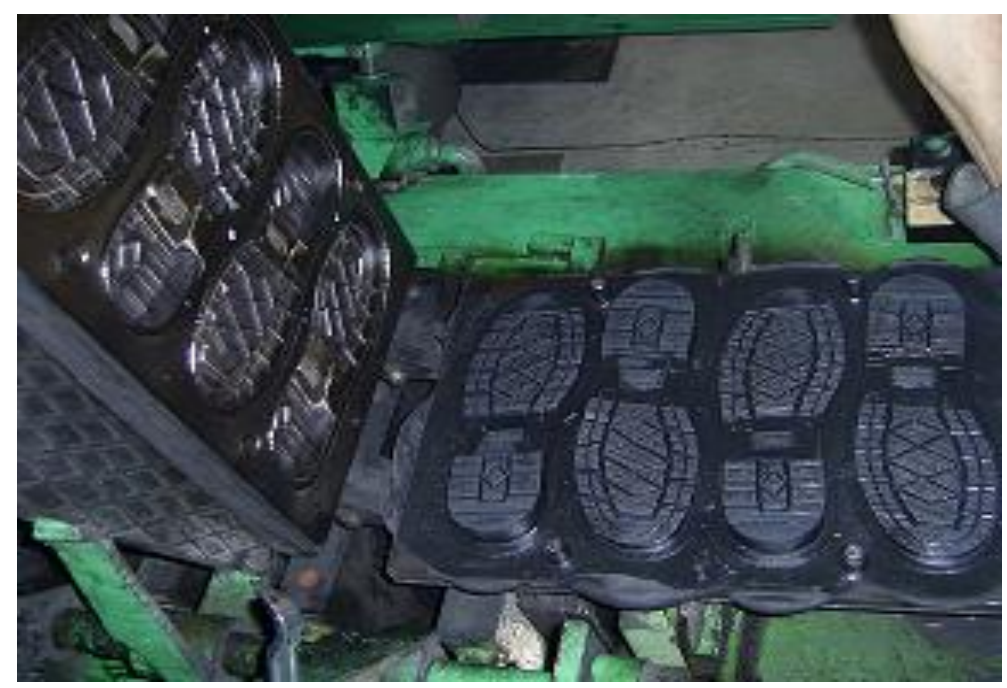

\section{Kauçuk Taban İmalatında İş Sağlığı ve Güvenliği}

Şekil 4. Vulkanizasyon sonrası tabanların çıkarılması [2]

Bütün kauçuk ve polimer işleme teknolojilerinde olduğu gibi kauçuk imalat sektöründe de iş sağlığ 1 ve güvenliği giderek daha da fazla önem kazanmaktadır. Son zamanlarda işyerlerinde meydana gelen ciddi kazalar, ortamda maruz kalınan koşullardan kaynaklanan önemli meslek hastalıklarının üzerini örtmektedir. 
Bazı meslek hastalıklarının fark edilir hale gelmesi, uzun yıllar almaktadır. Bu hastalıkların gizli kalma süreçlerinden ötürü işçinin yıllarca çalıştığı işyerinden ayrıldıktan sonraki geçirdiği zamanlara denk gelebilmektedir.

Yıllar içinde işçi çalışırken gelişen hastalık kendini gizleyebilmekte ve işçi çalışmayı bıraktıktan sonra fark edilmektedir. Bazı hastalıkların kaynağı işyeri ortamında maruz kalınan kimyasal maddeler olmasına rağmen, bunların birçoğu meslek hastalığı olarak teşhis edilmemektedir. Bunlarla birlikte, araç lastiği, hortum, kauçuk taban imalatında çalışan işçiler arasında kanser gibi ciddi hastalıklara da rastlanmaktadır. Uluslararası Çalışma Örgütünün (ILO) verilerine göre, araç lastiği imalat sektöründe çalışan işçiler üzerinde yapılmış olan bilimsel çalışmalar, mesane, mide, akciğer ve çeşitli kanserlerden dolayı ölüm oranlarının normalden yüksek olduğunu ortaya koymaktadır. Bu ölümler genelde spesifik bir kimyasala maruz kalınmış olmaya bağlanamamaktadır. Daha çok imalat aşamasında birden çok iş yapılırken kullanılan kimyasalların pek çoğuna maruz kalınmış olmasındandır. Kauçukla birlikte kullanılan katlı ve dolgu malzemelerinin formülasyon çeşitliliği ve vulkanizasyon sonucu bu malzemelerdeki değişmeler kanserlere tam olarak neyin sebep olduğunu ortaya çıkarmayı zorlaştırmaktadır [13].

Araç lastiği ve diğer kauçuk malzeme üretiminde çalışan işçiler arasında görülen diğer sağlık sorunları ise göğüs sıkışması, nefes darlığı, vb. solunum yolları ve solunum yollarının tahriş olması ile ilintili olan hastalıklardır. Anfizem, araç lastik imalat sektöründe ve diğer kauçuk sektörlerinde çalışanların erken emekliliklerine sebep olmaktadır.

Araç lastiği imalatı sırasında karıştırma, ezme, damak, kat, sırt, pişirme ve tetkik gibi üretim aşamaları sırasında çeşitli kimyasallar ve gazlara maruz kalınmaktadır. Bunların bir kısmı solunum yolları rahatsızlıklarına sebep olmaktadır.

Birçok işçide ise kontakt dermatit gibi cilt rahatsızlıklarına rastlanmaktadır. Lastik yapımında kullanılan kimyasal solventler, kükürt, yağlar, reçine, kauçuk ve karbon siyahları cildin tahriş olmasında etkili olabilmektedir.

Çalışma esnasında tekrar eden hareketler, titreşim ve basınç nedeniyle tenosinovit, karpal tünel sendromu, sinovit ve gürültüye bağlı işitme kaybı gibi travma rahatsızlıklarına sebebiyet verebilir.

Kauçuk ve türevi ürünlerle temas eden işçilerde cilt hastalıklarına sıkça rastlanmaktadır. Bu hastalıklar; iritan (tahrişe bağlı) kontakt dermatit, alerjik kontakt dermatit, kontakt ürtiker(kurdeşen), xerosis (kuru cilt), miliaria (Ter Retensiyon Sendromu, pişik, isilik) ve fenol türevlerinden kaynaklanan depigmentasyon. En çok görülen, güçlü kimyasallara, solventlere ya da nemli ortamlara maruz kalma nedeniyle görülen iritan kontakt dermatittir. Alerjik kontakt dermatit, kauçuk imalatı sırasında eklenen hızlandırıcılar, vulkanizatörler, antioksidanlar ve antiozonantlardan kaynaklanmaktadır. Bu maddeler bitmiş ürünlerde de bulunduğu için üretimin her aşamasında çalışan işçiler tarafindan dokunulduğunda ve maruz kalındığında kontakt dermatite neden olabilir [14].

Bazı işçiler bu hastalıklara kişisel koruyucu donanımlar kullanmadıkları için bazıları da bu koruyuculara karşı duyarlılık geliştirdikleri için yakalanmaktadırlar. Şüphelenilen alerjene karşı yapılacak tıbbı testler, alerjen kontakt dermatiti, iritan kontakt dermatitten ayırmak konusunda önemli olmaktadır çünkü unutulmamalıdır ki ikisi bir arada görülebilmektedir [15].

\section{Hastaliklar}

\subsection{Kimyasal Tehlikelerden Kaynaklanan Hastalıklar}

Kauçuk üretimi sırasında kauçuk veya kauçuk tozlarının el, yüz ve vücut bölümlerinin teması sonucu kontakt dermatit ve kauçukta bulunan doğal kauçuk lateks proteininden kaynaklanan lateks alerjisi görülebilir. Kontakt dermatit sadece kauçuktan değil kauçuk imalatı sırasında kullanılan diğer dolgu ve katkı türü kimyasallardan da kaynaklanabilir [5].

Etilen üretimi sırasında üretilen ve renksiz bir gaz olan 1,3 bütadien sentetik kauçuk üretiminde yaygın şekilde başlangıç malzemesi olarak kullanılır. Yapılan çalışmalar sonucu bu maddenin kanserojen olduğu ve özellikle lenf kanserine neden olduğu anlaşılmıştır [5].

Benzenin lösemi hastalığına neden olduğu anlaşıldıktan sonra sanayiide benzen kullanımı azalmış olsa da Türkiye'de kauçuk imalatında hala çalışanlara zarar verebilecek miktarlarda benzen kullanılmaya devam edilmektedir. İşyeri havasında bulunan benzen miktarı özellikle kauçuk hamurunun hazırlanması aşamasında yoğunluk gösterebilir [15].

Vulkanizasyon (pişirme) bölümünde ortaya çıkan dumanların solunması bu bölümde ve bu bölüme yakın yerlerde çalışan işçilerin vulkanizasyon işlemi öncesinde kullanılan kimyasalların zararlı etkilerini hissetmelerine neden olur. Bronşit bu bölümde çalışan işçilerde görülme riski artan bir hastalıktır. Ayrıca 409 | P a g e 
uzun yıllar kimyasal dumanlarını soluyarak çalışmak durumunda olan çalışanlarda kronik obstrüktif akciğer hastalığı (KOAH) görülme olasılığı artar. Ayrıca kauçuk üretimi sırasında talk pudrası kullanılan alanlarda çalışan işçilerde de KOAH görülme riski artar. Kauçuk imalatının neredeyse her aşamasında kullanılan kimyasallar solunum yollarının tahriş olmasına ve amfizeme neden olabilirler $[5,14,15,16]$.

\subsection{Fiziksel Tehlikelerden Kaynaklanan Hastalıklar}

Kauçuk üretiminin karıştırma aşamasında kullanılan ağır karıştırma makinelerinin ürettiği gürültü çalışanların işitme duyusunu kötü etkileyebilecek seviyelerde olabilir. Bu makinelerin yakınında uzun süreler çalışan işçilerde gürültüye bağlı işitme kaybı (GBIK) görülebilir [5].

Vulkanizasyon (pişirme) gibi sıcak işlemlerin yapıldığı ortamlarda çalışanların vücutlarının pres kalıbı gibi sıcak cisimlere temasıyla, sıcak sıvıların sıçramasıyla veya ısınmış kauçuğun vücuda temas etmesiyle, yanıklar oluşabilir.

\subsection{Kazalar}

Kauçuk malzemelerin üretiminde, çalışanlara zarar verebilecek birçok kimyasal madde kullanılır ve vulkanizasyon esnasında ortaya çıkar. Bunlar, katkı madde olarak, tozlar, katılar, yağlar ve polimerler; ısınma sırasında ortaya çıkan buğu ve buharlar ve tutkallarda seyreltici olarak kullanılan solventlerdir. Bu kimyasalların kullanımı ve karıştırılması sırasında yanlış bir uygulama yangına neden olabilir [5]. Kauçuk tozu kolay yanabilen bir maddedir. Ortamda ve belirli toz toplama bölümlerinde biriken organik tozlar da patlamaya ve yangına neden olabilirler. Kauçuk imalathanelerinde kullanılabilen, sülfür gibi, bazı kimyasalların tozları da yangına neden olabilir.

Kauçuk imalathanelerinin depolarında bulunan kimyasallarında uygun şekilde saklanmaması ve gerekli tedbirlerin alınmaması yangın ve patlamaya neden olabilir.

Kauçuktan yapılan malzemelerin vulkanizasyon sonrası dışarıdan belli olmayacak şekilde içten, alev almadan, uzun süren yanma (yavaş yanması) fark edilmediği takdirde ortaya çıkan duman çok çeşitli zehirli kimyasallar ve tanecikler içerir. Bu havayı uzun süre soluyan çalışanlar zehirlenebilir [5, 15].

Kauçuk imalatında kullanılan makineler özellikle de araç lastiği imalatında kullanılanlar oldukça büyük ve güçlü makinelerdir. Bu makineler kauçuğa şekil vermek, kauçuğu sıkıştırmak ve kesmek için kullanılırlar. Bu makinelerin kullanımı sırasında çalışanların özellikle parmak, el ve kolları kesilme veya kopma riskine karşı dikkatli olmalıdırlar.

\section{Kauçuk İmalatında Sağlık ve Güvenlik Önlemleri}

Dermatit ve lateks alerjisi gibi sağlık sorunlarından korunabilmek için kullanılan kimyasallar ve yeni üretilen kauçuk balyaları taşıma esnasında çıplak vücuda temas etmemelidir. Eğer kullanılan ekipman ve teknoloji gereği bunlara temas etmek zorunluysa, eldiven ve uzun kollu kıyafetler giyilerek cilde temas önlenmelidir. İş kıyafetleri sadece iş yerinde giyilmelidir. İş elbiseleri sık sık yıkanmalıdır. İşveren; işis biten işçilerin duş alabilmesi için uygun ortamlar sağlanmalıdır.

Kauçuğun vulkanizasyonu esnasında açığa çıkan bütadien vb gibi zararlı gazların buharlarından korunmak için kapalı devre sistemlerindeki bağlantı parçalarının yıpranmış veya yanlış bağlanmış olmamasına dikkat edilmelidir. Ayrıca vanalardan sızıntı olmaması için çift mekanik keçe kullanılmalıdır. Kullanılması zorunlu olan kimyasallardan çalışanların korunması için kimyasal buharlarının, tozların ortaya çıktığ1, vulkanizsayon gibi, işlerin yapıldığı alanların diğer çalışma alanlarından ayrılması gerekir. $\mathrm{Bu}$ alanlarda ve bu alanlara yakın yerlerde çalışan işçilere kullanılan kimyasalların Malzeme Güvenlik Bilgi Formları (MSDS) incelenerek alınması gereken güvenlik tedbirleri ve kullanılması gereken Kişisel Koruyucu Donanım malzemeleri seçilmelidir.

Kimyasal buharlarının bulunduğu ortamlarda çalışmak durumunda olan işçilerin periyodik sağlık kontrolleri yapılmalıdır. Bu ortamda çalışanların soluduğu kimyasalların verebileceği zararlar hakkında bilgilendirilmeli ve belli periyotlarla sağlık testleri yapılmalıdır. Böylece, çalışanın herhangi bir hastalığa yakalanmadan erken teşhis edilmiş olur $[4,14]$.

Kimyasalların yoğun olarak kullanıldığg her iş kolunda olduğu gibi kauçuk imalatında da ortamın havalandırılması çok önemlidir. Lokal ve genel havalandırma sistemleri kurulurken çalışma alanının büyüklügü̈, yapılan için hacmi ve çalışan sayısı, dikkate alınarak yapılmalıdır.

Yüksek gürültü çıkararak sesli çalışan makinelerde çalışan işçilere uygun kulak koruyucular temin edilmelidir. Ayrıca, vücutta olabilecek yanıklara karşı da uygun eldiven ve koruyucu giysiler giyilmelidir.

410 | P a g e

www.iiste.org 
Göz, eller, kollar ve yüz kimyasal madde sıçramalarına karşı korunmalıdır.

Depolarda ve kullanım sırasında, kimyasallardan kaynaklanan yangınlardan korunmak için kullanılan tüm kimyasalların Malzeme Güvenlik Bilgi Formları (MSDS) edinilmeli ve depo düzenlemeleri bunlara uygun şekilde yapılmalıdır. Kullanım sırasında yanlış karıştırmalardan kaynaklanan yangın ve patlamaların önlenmesi için de MSDS formları rehber alınarak hangi kimyasalların hangileriyle tepkimeye gireceği anlaşılabilir. Yine bu formlara bakılarak çıkabilecek yangın çeşitleri belirlenmeli ve bu yangınlara uygun yangın söndürme cihazlarının ortamda bulundurulması sağlanmalıdır. Tozlardan çıkan yangınları önlemek için toz biriken makine bölümleri sıklıkla temizlenmelidir [5].

Kullanılan makinelerin siper ve koruyucularının olması çalışanlara zarar gelmemesi için çok önemlidir. Ayrıca, bozulmuş veya kullanılmayacak durumda olan makinelerin etiketlenerek çalışma ortamından uzaklaştırılması gerekir. Aksi durumda, makine bilmeden çalıştırılabilir ve kullanan çalışan zarar görebilir. Kilitleme ve etiketleme sistemi ile hangi makinenin tamir edileceği ve hangisinin tamamen kullanımdan kaldırılacağı kolayca anlaşılacağından çalışanlar bu makineleri kullanmayacaklardır [5].

\section{Kauçuk İmalatında Kullanılan Makinelerde Güvenlik Önlemleri}

\subsection{Bamburi Makinesi}

Bamburi; kauçuk ve diğer katkı ile dolgu maddelerini yoğurarak hamur haline getiren makinedir. Yatay olarak duran iki adet silindirin ortasında yoğrulan kauçuk dönen ön silindirin etrafına sarılarak şerit haline gelir. Operatör, şeridi bir yerinden keserek üst taraftaki silindirlere yönlendirir. Süreç silindirlerin ortasında bulunan kauçuk bittikçe tekrar başa dönülerek devam eder.

Işslem sıcak kauçukla yapıldığı için operatörün eldiven takması gereklidir. Silindirlerin ortasındaki birleşme noktaları, operatörün el, parmak ve kolu için bir tehlike oluşturur. Ayrıca, operatörün kıyafetleri de silindirlerin arasına takılabilir. Bu nedenle operatörün üzerinde bol giysiler, bileklik, kravat gibi sıkışabilecek eşyalar bulunmamalıdır. Silindirin arasında sıkışabilecek bıçak ve eldivenler de kontrollü kullanılmalıdır.

Operatörün işini yapmasını engellemeden makinenin önüne konulacak bir engel operatörün silindirlere fazla yaklaşmasını önleyeceğinden el ve kollarının sıkışmasını engelleyebilir. Fakat bu engelin ve silindirlerin yüksekliğinin operatörün boyuna göre ayarlanması gereklidir.

\subsection{Kalenderleme Makinesi}

Kalenderleme makinesi, ters yönde dönen iki silindirin çekme kuvveti oluşturması yoluyla içinden geçirdiği kauçuğun istenilen kalınlığa getirilmesi için kullanılan bir makinedir. Silindirlerin birbirlerine en yakın oldukları kısımda kauçuk malzemenin sokulacağı bir açıklık vardır. Kauçuk bu açıklıktan girer ve belirlenen rotayı takip eder.

\subsection{Giyotin Makinesi}

Giyotin makinesi, bamburide levha haline gelmiş olan kauçuğun istenilen boyda kesilmesi için kullanılır. Giyotin bıçağının yukarıdan aşağıdaki zemin üzerine inmesi ile kesim yapılabildiği gibi bazı makinelerde bıçak sabit durur ve tabla yukarı çıkmaktadır. İki durum da operatör için aynı tehlikededir. Çalışanın parmakları veya eli kesinlikle bıçağın dikey hizasına denk gelmemelidir. Bunun için tabla üzerinde sınır işaretleri bulunmalıdır. Kesimin yapılacağı zeminde kesilecek parça dışında hiçbir şey bulunmamalıdır. Makine kullanılmadı̆̆ında bıçak aşağıda ve kilitlenmiş durumda bırakılmalıdır.

Yurt dışından ithal edilen makineler çalışma ortamına geldiğinde yabancı dilde olan kullanım kılavuzu anlaşılamadığından veya makinenin kullanımı sırasında nasıl kazalarla karşılaşabileceği bilgisi sağlanmadığından, kazalar ancak deneyimlenerek öğrenilebilmektedir.

Makine ile birlikte alınan makine koruyucu aksesuarlar da ancak kazalar yaşandıktan sonra kullanılmaya başlanmaktadır. Kalenderleme makinesinin silindirleri arasına el, kol ve parmaklar sıkışabilir. Ayrıca, silindirlerin dönüşünü sağlayan çıkrık sistemlerinin bulunduğu kenarlar da çalışanlar için tehlikelidir. Bu nedenle, makinenin kullanımı sırasında makine koruyucularının silindir açıklıklarını ve kenar çıkrıklarını kapatacak şekilde yerlerinde bulunmaları çok önemlidir [4, 14].

Makinede, hızı ayarlama, makineyi durdurma, ters yönde hareket ettirmeyi sağlayan bir düğme olmalıdır. Makine çalışmaya başlamadan önce ses ile veya uyarı lambaları ile çalışanları uyaran bir sisteme sahip olmalıdır. Makinenin başlangıç hızı düşük olmalıdır, çalışmaya devam ettikçe gerçek üretim hızına 411 | $P$ a g e www.iiste.org 
ulaşması operatörün kontrolü için faydalı olacaktır.

Makinenin temizliği silindirler sabitken yani makine kapalıyken yapılmalıdır. Makinenin kullanımı sırasında bir tehlike olması durumunda müdahale etmek için ortamda operatör haricinde bir kişi daha bulunmalıdir.

\section{Sonuç}

Kauçuk taban imalatı yapan işletmelerde sağlık ve iş güvenliği koşulları dikkate alınarak yapılan çalışmada hamur karışımında kullanılan katkı ve dolgu malzemelerinin karıştırılması ve vulkanizasyon esnasında ortaya çıkan zararlı maddeler ve bunların sebep olduğu olası meslek hastalıkları ve alınması gereken güvenlik önlemleri bu çalışmanın içeriğini oluşturmaktadır.

Elastomerlerin kullanım alanının çok geniş olması ve kauçuk işleme tekniklerinin gelişerek artması her geçen gün sektörde çalışanların sayısını artırmaktadır.

Doğal ve sentetik yollarla elde edilen kauçuklar farklı dolgu ve katkı maddelerini içinde bulundururlar. Vulkanizasyon sonrası şekillendirilme esnasında yüksek sıcaklıklarda 1sıl işleme maruz kaldıklarından ortama farklı gazlar, duman ve buharların salınımı gerçekleşir. Ayrıca çalışma esnasında; cilt yanıkları, kesikler, uzuv kopmaları yada sıkışması, yüksek gürültü nedeni ile zaman içinde işitme kayıpları ve tekrarlı hareketler sonucu kas rahatsızlıkları kauçuk iş kolunda meydana gelebilecek kazalardan bazılarıdır.

Kauçuk sektöründeki tehlikelerden korunmak için en etkin yaklaşım hastalık ile temasın önlenmesidir. İşletmede oluşabilecek riskleri bilmeden önlem alması mümkün değildir. Yaptırılacak bir risk analizi raporuna göre olası kaza ve meslek hastalıklarını ortadan kaldıracak şayet bu mümkün değil ise kaza ve meslek hastalıklarını en az düzeye indirecek tedbirler alınmalıdır. Ayrıca hastalıklara sebep olan maddeleri kullanmak yerine daha az zararlı alternatif veya zararsız maddeleri tercih edilmelidir.

Özellikle hamur yoğurmada kapalı sistem bamburilerde çalışmak, iyi izolasyon ve havalandırma, kişisel koruyucuların doğru tespit edilmesi ve kullanılması, personelin olası kazalara karşı eğitilmesi ve çalışanların düzenli olarak sağlık kontrolünden geçirilmesi gerekmektedir. Kauçuk iş kolunda meslek hastalıklarının erken teşhisi çok önemlidir.

\section{Kaynakça}

[1] Akçakale N., Ayakkabı Malzeme Teknolojisi, Gece kitaplığı, Ankara, 2017

[2] Akçakale N., (2008), NR/SBR Tipi Elastomer Esaslı Ayakkabı Taban Malzemelerinin Mekaniksel Özelliklerine Bazı Dolgu Maddelerinin Etkilerinin İncelenmesi, Sakarya Üniversitesi Fen Bilimleri Enstitüsü, Doktora Tezi, Sakarya

[3] http://www.hurriyet.com.tr/ekonomi/turkiyede-kisi-basina-yilda-uc-cift-ayakkabi-dusuyor40742212

[4] http://www.hse.gov.uk/rubber/introduction-to-rubber-processing.pdf

[5] https://www.isguvenligi.net /iskollari-ve-is-guvenligi /kaucuk-imalatinda-is-sagligi-guvenligi/

[6] http://www.kmo.org.tr/resimler/ekler/2cf91cbfb407a6d_ek.pdf?tipi=2\&turu=H\&sube=1

[7] Egwaıkhıde, P.,A., Akporhoner, E.,E., Okıeımen, F., E., Effect of Cocount Fibre Filler on the Cure Characteristics Hysico-Mechnical and Selling Properties of Natural Rubber Vulcanisates., International Journal of Physical Sciences Vol. 2, February, 2007

[8] Babbit, O.R., The Vanderbilt Rubber Handbook, Vnaderbilt Company Inc. 30 Wifield Street, Norwalk, C. T.,USA, 1978

[9] Kauçuk ve Elastomer Teknolojisi, Kauçuk Derneği Seminer Notları, İstanbul, Kauçuk Derneği,

412 | $\mathrm{P}$ a g e

www.iiste.org 
İstanbul, 1998

[10] Savran, Ö., H., Elastomer Teknolojisi 1, Kauçuk Derneği Yayınları, İstanbul, 2001

[11] Akcakale N., "Filling Materials and Properties of Rubber Type Elastomers", International Journal of Scientific and Technological Research, 2019/1, Cilt, 5 Sayı 1, Sayfalar 171-181

[12] Encyclopedia of Polymer Science and Engineering, a Willey Interscience Publication, Volume 16, U.S.A., 1989

[13] Savran, Ö., H., Elastomer Teknolojisi 2 Temel Elastomerler, Kauçuk Derneği Yayınları, İstanbul, 2002

[14]http://www.akaisguvenlik.com/lastik-ve-kaucuk-imalat-sektorunde-is-sagligi-ve guvenligi/23/oku.html

[15] Beliczky L. S., Fajen J., Rubber Industry. ILO Encyclopaedia of Occupational Health and Safety. http://www.ilo.org/iloenc/part-xii/rubber-industry

[16] Kılıç Timuçin, Ö., Kauçuk Sektöründe Karşılaşılan Kimyasal Tehlikeler ve Çalışanların Bu Tehlikelerden Korunması. İş Sağlığı ve Güvenliği Merkezi Müdürlüğü. 